\title{
Occupational Therapy in the Process of Recovering from Severe Mental Disorder
}

Efrén Valverde-Bolivar

Catholic University of Murcia

Agustín Javier Simonelli-Muñoz ( $\sim$ sma147@ual.es )

University of Almería

José Miguel Rivera-Caravaca

Hospital Clínico Universitario Virgen de la Arrixaca, Instituto Murciano de Investigación Biosanitaria (IMIB-

Arrixaca), CIBERCV

Juana Inés Gallego-Gómez

Catholic University of Murcia

María Teresa Rodríguez González-Moro

Catholic University of Murcia

José J. García-Arenas

Catholic University of Murcia

\section{Research Article}

Keywords: Severe Mental Disorder, Occupational Therapy, Activity, Intervention, Perception.

Posted Date: June 7th, 2021

DOI: https://doi.org/10.21203/rs.3.rs-589391/v1

License: (c) (i) This work is licensed under a Creative Commons Attribution 4.0 International License. Read Full License 


\section{Abstract}

Background Severe mental disorder (SMD) produces a significant functional limitation that affects the performance of daily activities. This limitation is where the occupational therapist intervenes by seeking greater autonomy of these patients through specific activities. This study aims to identify the main limitations of people with SMD and see whether an occupational intervention has any effect in helping to overcome or ameliorate these limitations.

Method An experimental study consisting of 103 subjects was carried out, where an evaluation was given before and after the intervention. The tool used is called the WHODAS questionnaire included in the DSM 5.

Results Within the programming of activities, those with a higher attendance rating during cognitive stimulation, cooking workshop, therapeutic walks, relaxation, and creative activities were mainly men. The results showed that both patients and professionals indicated that Understanding and Communicating, Participation in Society, and Activities of Daily Living were the main perceived limitations. Upon discharge, both patients and professionals saw positive outcomes.

Conclusion The intervention programs carried out by Occupational Therapy, along with the other aspects of the treatment that the patients with SMI have received, have played a part in improving the performance and occupational interests of the patients.

\section{Background}

During the most recent decades, a vast effort has been made to improve therapeutic approaches in mental health. Severe Mental Disorder (SMD) ${ }^{(1)}$ nowadays is one of the fields in which more research is being done. SMD encompasses a series of disorders such as schizophrenia, schizotypal personality disorder, delusional disorder, schizoaffective disorder, other specified schizophrenia spectrum or other psychotic disorders, bipolar I disorder with psychotic features, major depressive disorder with psychotic features, and obsessive-compulsive disorder ${ }^{(2)}$. Its diagnosis includes at least two of the following criteria ${ }^{(3)}$ :

1. Unemployment (including sheltered or supported employment), clearly limited skills, or poor work history.

2. Need for public financial support to stay out of hospital who may require support to obtain such help.

3. Difficulties in establishing or maintaining personal social support systems.

4. Need for help with daily life skills, such as hygiene, food preparation, or financial management.

5. Inappropriate social behavior that determines psychiatric or judicial assistance.

These disorders, among others, produce a significant functional limitation in carrying out Activities of Daily Living (ADLs). Therefore, one of the main challenges in the intervention of individuals with SMD is to improve their ADLs. In this regard, to meet individuals' needs, these interventions should be focused on a collaborative relationship between professionals, the patient, and their family ${ }^{(4)}$. Therefore, the therapeutic approach must be adapted to interdisciplinary teams, supported by pharmacological treatment and others. 
By adopting this perspective, the person is treated from a holistic point of view, which considers the different human, biological and psychological dimensions in family and social life ${ }^{(5)}$.

Occupational Therapy has an essential role in the treatment, especially the prognostic ${ }^{(6,7)}$. It is described as "the profession responsible for promoting health and well-being through occupation and whose objective is to work with people and communities to improve their skills and employment in the occupation they want, need or is expected according to their conditions, or modifying the occupation or the environment to improve their participation ${ }^{(8) "}$. Among the aims is the search for greater autonomy and, in the field of mental health, the reintegration of the patient using the community as an occupational element, basing the interventions on the model of human occupation ${ }^{(9)}$.

For all of the above, the objectives of the present study are to identify the main limitations of people with SMD and examine whether an occupational intervention has any effect in helping to overcome or improve these limitations.

\section{Method}

\section{Design of Study}

A qualitative experimental study was carried out with three interventions: an intra-subject factor, time (evaluation before vs. after the intervention), and another between subjects (self-assessment vs. patient assessment by a professional and vice versa) and another factor within and between subjects, their sociodemographic circumstances (in which time (admission vs. discharge) and self-evaluation of the patient and the professional were evaluated). The dependent variable was the occupational performance of people with a form of a diagnosed SMD, which roughly consists of carrying out activities such as ADLs, education, work, play, and social participation.

\section{Sample}

The study sample is comprised of those diagnosed with SMD and admitted to the Regional Unit for Medium Stay (URME) in Murcia, Spain, from September 2016 to December 2017. In terms of the user profile, they are patients who require an extended admission in order to recover. Other local mental health resources refer patients to URME, and after the committee has approved, they are welcomed and admitted to the unit. Previously, the purpose of the study was explained to the users, and the informed consent was signed. Confidentiality of data was guaranteed at all times, respecting the agreements of the Declaration of Helsinki.

\section{Admission Criteria}

The following inclusion criteria were taken into account: being over 18 years of age, being in treatment in the unit, not showing signs of active symptoms (delusions, hallucinations, psychomotor agitation, or other uncommon symptoms) that interfere with the dynamics, and being willing to participate in the different 
programs carried out by occupational therapists. Once the examiner explained the study's objectives and procedures, the patients who did not sign the informed consent were excluded ( 2 users).

\section{Sample Definition}

The final sample consisted of 103 subjects ${ }^{(10)}$, of which 89 were able to be reevaluated within the study timeframe, whereas 14 patients were unable to be reevaluated at the end of the study since they were discharged. A sample size (n) of approximately 100 individuals was sought to obtain the statistical significance required for this type of research ${ }^{(11,12)}$.

\section{Data Collection and Variables}

The approach was assessed by Occupational Therapy using the gathering of data. Two evaluations were carried out after the sociodemographic analysis of the population of individuals, one upon admission of the patients and the other after the intervention, just before they were discharged. In addition, these evaluations were carried out both by the patients themselves and by the health professionals.

Initially, sociodemographic data that complements the previous scales was collected, such as sex, age, educational level, family situation, and the number of hospital admissions.

The research instrument for collecting information about the occupational performance was the World Health Organization Disability Assessment Schedule Questionnaire (13) (WHODAS 2.0). The WHODAS scale is a research instrument that frequently provides information about disabilities in different populations, such as schizophrenia ${ }^{(14)}$. This assessment instrument is translated and validated in many different languages, including Spanish ${ }^{(15)}$.

This tool consists of 7 factors that showed acceptable, reliable indices in each of the measurements:

1. Understanding and Communicating (UC: $0.751<\mathrm{a}<0.879$ );

2. Community Mobility (CM: $0.833<\mathrm{a}<0.913)$;

3. Personal Care(PC: $0.796<\mathrm{a}<0.815)$;

4. Interpersonal Relationships (IR: $0.719<\mathrm{a}<0.771$ );

5. Activities of Daily Living (ADLs: $0.963<\mathrm{a}<0.986$ );

6. Work and Daily Activities(WDA: $0.921<\mathrm{a}<0.966)$;

7. Participation in Society (PS: $0.590<\mathrm{a}<0.803$ ).

Although in this scale, the analysis of the results left out the factor WDA due to only a small number of employed participants $(\mathrm{N}=18)$. The response options were a qualitative five-point Likert-type scale, normalizing it to a quantitative value, from 1 (None) to 5 (Extreme), in this case; higher scores indicated a more severe case of their disability.

\section{Intervention}


Once admitted to the unit, the staff explained the patients' scheduled dynamics and activities. Later, after a week of adaptation and observing their participation, the initial evaluation was carried out. The Individual Recovery Plan (IRP) was established, taking into account the data obtained and the patient's goals. The IRP consisted of a team meeting with a psychiatrist, psychologist, social worker, nurses, and occupational therapist (OT). Each of the professionals posed goals to work towards after conducting their exploration with the OT to decide the different ADLs and their components. The OT took into account that the remaining variables of the IRP made the patients closer to baseline and standardized psychopathological characteristics. The different activities, their description, and their purpose are documented in Table 1. Ultimately, patients were reevaluated before discharge.

Additionally, the participants evaluated the professionals through a satisfaction survey once their admission becomes finalized.

\section{Data analysis and treatment}

The data was processed by SPSS version 250.0 (SPSS, Inc., Chicago, IL, USA), using Student's $t$-test comparing two variables, parametric multi-variant analysis ANOVA and linear correlations. All data obtained from the multivariate analysis are expressed as

$M \pm S D$ ot $\pm D T$.

First of all, descriptive parameters for user participation in occupational interventions were calculated. Secondly, several analyses of mean differences were conducted in order to check the variations of the factors of the WHODAS between admission and discharge of the patient and between self-evaluation of the patient and evaluation of the professional (taking into account the staff's patient evaluation). Finally, the differences in means were analyzed, taking into account some of the user's sociodemographic characteristics, which are included at the beginning of the results since they include parameters from both groups of the other means. Subsequently, the Statistics of the demographic variables previously collected were calculated in order to be analyzed.

Table 1. Description of the interventions and objectives. 
Interventionbjective

Cognitive Recover, stimulation maintain or delay this deterioration.

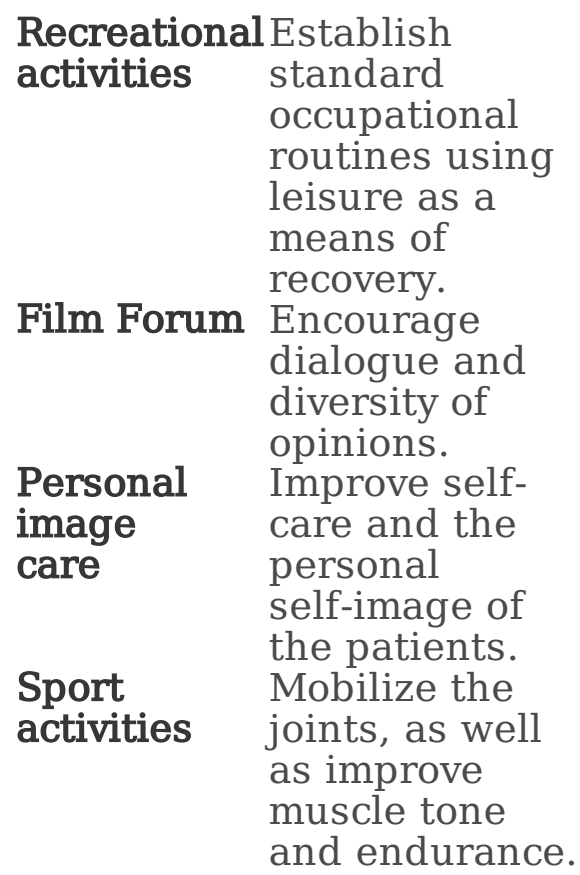

Relaxation Reduce anxiety levels through relaxation techniques

Training imcrease the ADLs autonomy and independence of patients.

Therapeutic Influence Outings autonomy or independence in the performance of AIVD.

Individualizedttend and interventionsmeet the needs of each of the patients.

Social skills Stimulate social interaction and offering them the opportunity to face and solve everyday problems

\section{Description}

A serious problem that we find in institutionalized people is the deterioration of cognitive functions. Therefore, training sessions were carried out through different exercises, developing interventions according to their abilities, in some cases on their own (cards and games), and in others, a group setting. Cognitive exercises were applied to everyday situations, such as shopping, reminiscence therapy, tasks in the community, and various types of treatments.

Patients participated in various entertainment activities consisting of different games, dynamics, creative activities, and outings. The entertainment aimed to merge their leisure time within a community context in an inclusive satisfactory way.

This program's activities consisted of the projection of a film. Then, according to the patients' interests, a series of exercises on different topics related to the film included guided discussion.

This program consisted of giving a series of indications and the necessary material to improve the personal image of the patients and their external appearance. Patients received aesthetic materic and dress guidelines.

Sessions took place in the unit; the location included the gym in the facility. For those who showed interest, resources were sough in the community for their continuity. Among the sports activities were: gymnastics, hiking, swimming, and various sports.

We performed different relaxation techniques, accompanied by music that enables a calm state, providing the restoration of serenity and control of tension after the sessions.

Training in ADLs was carried out, from essential clothing to more complex ones such as food, shopping, and community management.

The OC promoted therapeutic outlets to normalize and generalize previously trained behaviors, such as handling money, shopping, and taking the bus.

After the evaluation and according to individual needs, specific interventions were carried out, such as accompaniment to their home, public transport use, communication systems (mobile phone), and community management.

Different guidelines and exercises were established, such as roleplaying. The patients acted out everyday situations through reallife scenarios to solve daily problems with suggested alternatives from professionals. 


\section{Results}

In order to analyze the data more accurately, the WHODAS score differences were subsequently compared, according to both the patient's self-evaluation and the professional's evaluation. The analyses and results are presented below in the order listed above.

Initially, the study collected sociodemographic data from the patients. Of the 103 subjects, $49.8 \%$ were women, aged between 19 and 59 years $(M=41.38 ; S D=10.22)$. Regarding the level of education, $5.8 \%$ had not received any education, $46.6 \%$ had completed primary school, $35.9 \%$ at secondary school, and $11.7 \%$ at the university. In terms of their familial situation, $25.2 \%$ lived alone while $74.8 \%$ lived with someone. Of the total sample, 89 participants completed reassessment; the remaining 14 could only make the initial assessment. In total, the patients stayed in the facilities for an average of 119 days \pm 56.07 .

Secondly, the frequency of patients participating in occupational interventions was assessed. As shown in Table 2, cognitive stimulation, cooking workshops, therapeutic walks, relaxation, and creative activities were the activities in which most patients were involved.

Table 2. Participation of subjects in occupational interventions during the stay in the center - $\mathrm{N}$

\begin{tabular}{lcc}
\hline & $\mathrm{M}^{\mathrm{a}}$ & $\mathrm{SD}^{\mathrm{b}}$ \\
\hline Swimming & 1.27 & 2.24 \\
Cognitive stimulation & 9.42 & 7.82 \\
Social skills & 5.20 & 4.05 \\
Kitchen skills & 10.29 & 9.48 \\
News & 7.49 & 8.16 \\
Therapeutic outings & 10.63 & 8.59 \\
Gym & 8.58 & 9.08 \\
Relaxation & 9.87 & 9.88 \\
Music therapy & 5.71 & 4.66 \\
Allotment work & 2.70 & 3.87 \\
Aesthetic workshop & 3.95 & 4.57 \\
Creative Workshop & 8.69 & 14.25 \\
Film Forum & 1.33 & 1.81 \\
\hline
\end{tabular}

${ }^{\mathrm{a}} \mathrm{M}$ : Mean; ${ }^{\mathrm{b}} \mathrm{SD}$ : Standard Deviation

Thirdly, an analysis was carried out to check the difference in factors relating to WHODAS before and after the intervention according to the patient's self-assessment. As shown in Table 3, significant differences were found in all factors. Specifically, the self-evaluation in each of the factors was more positive (lower) when they were discharged than when they were admitted, showing an improvement in the patients' selfperception regarding their limitations. The two factors in which the change was greater were Understanding and Communicating and Participation in Society, the factor that the patients found the most difficult as a whole was Activities of Daily Living.

Table 3. Simple effects of time on the different factors of the WHODAS according to the patient's self-evaluation. 


\begin{tabular}{lccccc}
\hline & Income $\mathrm{M}^{\mathrm{a}}\left(\mathrm{SD}^{\mathrm{b}}\right)$ & High M$^{\mathrm{a}}\left(\mathrm{SD}^{\mathrm{b}}\right)$ & $\mathrm{t}$ & $\mathrm{p}$ & Cohen's d \\
\hline $\mathrm{UC}^{\mathrm{c}}$ & $2.25(.80)$ & $1.60(.61)$ & 6.943 & 0.000 & 1.07 \\
$\mathrm{CM}^{\mathrm{d}}$ & $1.56(.78)$ & $1.32(.62)$ & 3.427 & 0.001 & 0.34 \\
$\mathrm{PC}^{\mathrm{e}}$ & $1.39(.68)$ & $1.23(.47)$ & 2.355 & 0.021 & 0.27 \\
$\mathrm{IR}^{\mathrm{f}}$ & $2.16(.80)$ & $1.79(.70)$ & 4.023 & 0.000 & 0.49 \\
$\mathrm{ADLs}^{\mathrm{g}}$ & $2.24(1.06)$ & $1.63(.82)$ & 5.077 & 0.000 & 0.64 \\
$\mathrm{PS}^{\mathrm{h}}$ & $2.42(.72)$ & $1.83(.52)$ & 2.742 & 0.023 & 0.94 \\
\hline
\end{tabular}

${ }^{a}$ M: Mean; ${ }^{b} S D$ : Standard Deviation; t: Student's t; p: Statistical Significance; ${ }^{c} U C$; Understanding and Communicatig; ${ }^{\mathrm{d}} \mathrm{CM}$; Community Mobility; ${ }^{\mathrm{e} P C}$; Personal Care ${ }^{\mathrm{f} I R \text { : }}$ Interpersonal Relationships;

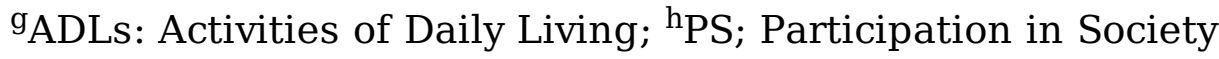

Fourthly, the same analyses were carried out, but, in this case, using the professional's patient evaluation. As shown in Table 4, there were significant differences in all the WHODAS factors. Self-evaluations by the patients and the professionals' assessments both found a more positive outcome when discharged than initial admission. The analysis showed improvements from both patients and professionals. Regarding the patients' self-evaluation, the two factors in which there was a more significant change were Understanding and Communicating and Participation in Society. These two factors were also those that received the most negative evaluation from the professionals, together with Activities of Daily Living and Interpersonal Relationships. In contrast to the patients' view, Interpersonal Relationships were unrecognizable as a more significant barrier.

Table 4. Simple effects of time on the different WHODAS factors according to the professional's evaluation - Murcia, Spain, 2016-2017.

\begin{tabular}{lccccc}
\hline & Income $\mathrm{M}^{\mathrm{a}}\left(\mathrm{SD}^{\mathrm{b}}\right)$ & High M $^{\mathrm{a}}\left(\mathrm{SD}^{\mathrm{b}}\right)$ & $\mathrm{t}$ & $\mathrm{p}$ & Cohen's d \\
\hline $\mathrm{UC}^{\mathrm{c}}$ & $2.47(0.64)$ & $1.77(0.56)$ & 12.277 & 0.000 & 1.16 \\
$\mathrm{CM}^{\mathrm{d}}$ & $1.50(0.67)$ & $1.29(0.56)$ & 3.170 & 0.002 & 0.34 \\
$\mathrm{PC}^{\mathrm{e}}$ & $1.60(0.63)$ & $1.34(0.49)$ & 5.095 & 0.000 & 0.46 \\
$\mathrm{IR}^{\mathrm{f}}$ & $2.56(0.69)$ & $2.03(0.60)$ & 8.102 & 0.000 & 0.82 \\
$\mathrm{ADLs}^{\mathrm{g}}$ & $2.78(0.87)$ & $1.99(0.80)$ & 9.300 & 0.000 & 0.95 \\
$\mathrm{PS}^{\mathrm{h}}$ & $2.50(0.62)$ & $1.87(0.47)$ & 8.812 & 0.000 & 1.15 \\
\hline
\end{tabular}

${ }^{a}$ M: Mean; ${ }^{b} S D$ : Standard Deviation; t: Student's t; p: Statistical Significance; ${ }^{C} U C$; Understanding and Communicatig; ${ }^{\mathrm{d}} \mathrm{CM}$; Community Mobility; ${ }^{\mathrm{e}} \mathrm{PC}$; Personal Care ${ }^{\mathrm{f}} \mathrm{IR}$ : Interpersonal Relationships;

gADLs: Activities of Daily Living; ${ }^{\text {hPS}}$; Participation in Society

Fifthly, a repeated measures analysis was performed with an intra-subject factor (Time: Admission vs. Discharge) and a factor between subjects (Evaluator: Patient vs. Expert) in order to check whether there were differences between the patient's self-assessment and the professionals' self-assessment, as well as the time when the measure was taken. The results only showed a significant interaction in Interpersonal Relationships (IR) (Table 5). Specifically, the evaluation of the patient in the IR was lower at discharge than 
at the beginning. However, when the patient was the evaluator, the patients' assessment showed an even lower than when it was the professional. No significant differences were found in the other factors, so we can affirm that both the patients' self-evaluation and the professionals' evaluation were similar when they were admitted and discharged.

Table 5. Interaction between time and the evaluator in the different factors of the WHODAS - $\mathrm{N}$

\begin{tabular}{|c|c|c|c|c|c|c|c|}
\hline & \multicolumn{2}{|c|}{ Patient } & \multicolumn{2}{|c|}{ Professional } & \multirow{3}{*}{$\mathrm{F}$} & \multirow{3}{*}{$\mathrm{p}$} & \multirow{3}{*}{$\mathrm{h}^{2}{ }_{\mathrm{p}}$} \\
\hline & Entry & high & Entry & high & & & \\
\hline & $\mathrm{M}^{\mathrm{a}}\left(\mathrm{SD}^{\mathrm{b}}\right)$ & $\mathrm{M}^{\mathrm{a}}\left(\mathrm{SD}^{\mathrm{b}}\right)$ & $\mathrm{M}^{\mathrm{a}}\left(\mathrm{SD}^{\mathrm{b}}\right)$ & $\mathrm{M}^{\mathrm{a}}\left(\mathrm{SD}^{\mathrm{b}}\right)$ & & & \\
\hline $\mathrm{UC}^{\mathrm{c}}$ & $2.25(0.80)$ & $1.60(0.61)$ & $2.47(0.64)$ & $1.77(0.56)$ & 0.759 & 0.386 & 0.008 \\
\hline $\mathrm{CM}^{\mathrm{d}}$ & $1.56(0.78)$ & $1.32(0.62)$ & $1.50(0.67)$ & $1.29(0.56)$ & 0.344 & 0.559 & 0.004 \\
\hline $\mathrm{PC}^{\mathrm{e}}$ & $1.39(0.68)$ & $1.23(0.47)$ & $1.60(0.63)$ & $1.34(0.49)$ & 2.683 & 0.105 & 0.029 \\
\hline$I^{f}$ & $2.16(0.80)$ & $1.79(0.70)$ & $2.56(0.69)$ & $2.03(0.60)$ & 5.313 & 0.023 & 0.056 \\
\hline $\mathrm{ADLs}^{\mathrm{g}}$ & $2.24(1.06)$ & $1.63(0.82)$ & $2.78(0.87)$ & $1.99(0.80)$ & 3.080 & 0.083 & 0.033 \\
\hline $\mathrm{PS}^{\mathrm{h}}$ & $2.42(0.72)$ & $1.83(0.52)$ & $2.50(0.62)$ & $1.87(0.47)$ & 1.159 & 0.285 & 0.013 \\
\hline
\end{tabular}

${ }^{\mathrm{a}} \mathrm{M}$ : Mean; ${ }^{\mathrm{b}} \mathrm{SD}$ : Standard Deviation; t: Student's t; p: Statistical Significance; ${ }^{\mathrm{c} U C}$; Understanding and Communicatig; ${ }^{\mathrm{d}} \mathrm{CM}$; Community Mobility; ${ }^{\mathrm{e}} \mathrm{PC}$; Personal Care ${ }^{\mathrm{f}} \mathrm{IR}$ : Interpersonal Relationships;

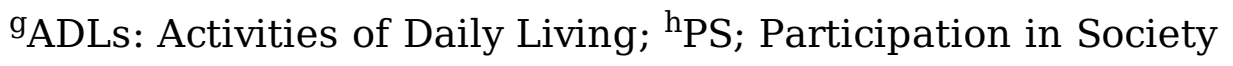

Finally, different analyses were carried out to check whether there were differences in the different WHODAS factors, taking into account some sociodemographic variables and, in other cases, whether there was a correlation between the two. The results presented are mainly related to sex, age, educational level, familial situation, and the number of previous admissions. Only the data showing significant differences in the WHODAS evaluations are shown due to the large number of analyses for each factor.

In the case of gender, differences in the PS factor were found in the self-assessment of the patients upon admission $(t=3.060, p=0.003)$. Specifically, women $(2.70 \pm 0.81)$ presented a higher self-assessment than men $(2.26 \pm 0.66)$. On the other hand, in the self-evaluation they carried out when they were discharged, differences were found in the factors $\mathrm{CM}(t=2.408, p=0.020), \mathrm{PC}(t=2.026, p=0.049)$ and PS $(t=2.176, p$ $=0.032)$. In the three cases, women (CM: $1.53 \pm 0.80$; PC: $1.37 \pm 0.67 ; \mathrm{PS}: 1.97 \pm 0.54)$ presented higher self-evaluations than men (CM: $1.18 \pm 0.42$; PC: $1.13 \pm 0.24$; PS: $1.73 \pm 0.49)$.

Regarding the professionals' evaluations, in reference to the admission of the patients, differences were found in factors CM $(t=2.520, p=0.014)$, ADLs $(t=4.187, p<0.001)$ and PS $(t=2.872, p=0.005)$. Again, women (CM: $1.71 \pm 0.81$; PS: $M=2.73$, DT = 0.72) obtained higher evaluations than men (CM: $1.36 \pm 0.47$; PS: $2.36 \pm 0.50)$ in $C M$ and PS; however, men $(3.07 \pm 0.58))$ scored lower than women $(2.36 \pm 0.99)$ in ADLs. Regarding discharge, differences were found in $\mathrm{CM}(t=2.402, p=0.020)$ and ADLs $(t=2.052, p=$ 
0.044). Specifically, in CM, women (1.48 \pm 0.71$)$ scored lower than men $(1.17 \pm 0.40)$ and in ADLs, men $(2.13 \pm 0.72)$ scored lower than women $(1.77 \pm 0.88)$.

In the case of age, in the self-assessment of patients upon admission, only a negative correlation was found between age and UC $(r=-0.246, p=0.012)$, while in the self-assessment carried out when they were discharged, no correlation was found. When the evaluation was carried out by professionals, age was positively correlated with $\mathrm{CM}(r=0.307, p=0.002)$ and $\mathrm{PC}(r=0.240, p=0.014)$ during admission, while at discharge only a positive relationship was found with PC $(r=0.304, p=0.003)$.

In the case of the number of previous admissions to the hospital, correlations were also made. Upon admission, patients were given a self-assessment showing a significant positive relationship with UC ( $r=$ $0.202, p=0.04)$, whereas no significant correlation was found at discharge. During the professional's evaluation, the same positive relationship between the number of previous admissions and UC was significant $(r=0.203, p=0.039)$, and again at discharge, no significant relationship was found.

In the case of education, the patients' self-evaluations found no significant difference $(p=0.094)$ neither at discharge nor at admission. However, in the professional's evaluation, significant differences were found. At admission, significant differences appeared in UC $(F=3.120, p=0.029)$. A posthoc analysis by the Tukey method revealed that the differences were found between those with primary education $(2.62 \pm 0.59)$ and university education $(2.06 \pm 0.67)$, the former being the ones with the most difficulties. At discharge, significant differences were found in UC $(F=3.404, p=0.021)$ and ADLs $(F=2.758, p=0.047)$. In the case of UC, those with primary education had a worse prognosis $(M=1.93, S D=0.56)$ than those with secondary education $(1.60 \pm 0.48)$ or university education (1.46 \pm 0.40$)$; while in the case of ADLs, who had primary education $(2.21 \pm 0.75)$ had a worse prognosis than those with secondary education $(M=1.71 \pm$ $0.75)$.

Lastly, regarding the familial situation, significant differences appeared in $\mathrm{CM}$ during the self-evaluation at admission $(t=2.708, p=0.008)$. Those who lived with a family $(1.64 \pm 0.85)$ had a worse prognosis than those who lived alone $(1.32 \pm 0.34)$. No significant differences appeared at discharge. On the other hand, regarding the evaluation of the professionals, no significant differences were found either at admission or discharge.

\section{Discussion}

The objectives of the present study were to identify the main limitations of people with SMD and check whether an occupational intervention has any effect in helping to overcome or ameliorate these limitations. Different patients with SMD were evaluated after their hospital admission and just before discharge to measure their limitations. These evaluations included a study of their sociodemographic parameters, which is the core of this research. A biased is possible with self-assessments by the patients due to their social cognition $^{(16)}$. Therefore, these evaluations were carried out both by patients and by professionals.

During their admission, the patients participated in several interventions carried out through occupational therapy, hoping to improve the evaluations of their occupational performance. The results showed that both 
the patients and the professionals indicated that Understanding and Communicating, Participation in Society, and Activities of Daily Living were the main limitations they encountered ${ }^{(17)}$. However, only professionals indicated Interpersonal Relationships as a barrier. Most of the participants were not within the initial stages of the disease, which affects their level of functionality ${ }^{(18)}$.

On the other hand, the evaluation was more positive after the participation in occupational tasks. The improvement was especially significant in Understanding and Communicating and in Participation in Society. When comparing the evaluations made by patients and professionals, differences were only found in Interpersonal Relationships. This result shows that the patients overestimated their abilities to relate to other people. One possibility is that the patients were unaware of their illness symptoms. In this regard, when conducting the evaluations, it was observed that certain patients were unable to perceive their current situation when they were admitted. However, more time spent in the unit, together with psychopharmacological treatment and establishing a socio-occupational routine ${ }^{(19)}$, allowed the patients to acquire a greater awareness of their situation. Therefore, the individuals may have acquired a capacity of insight ${ }^{(20)}$, allowing them to obtain awareness of their current situation ${ }^{(21)}$.

Nevertheless, no significant differences were found in the other factors concluding that the patients' selfevaluation was similar to the professionals' evaluation. Therefore, no evidence was found that the

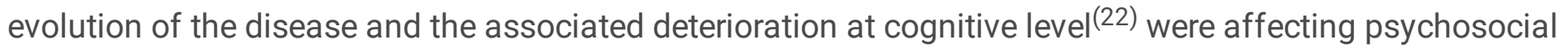
functioning ${ }^{(23)}$. Moreover, self-evaluations indicated that patients had acquired awareness of their illness. Finally, some differences were also found according to sociodemographic characteristics. Based on sex, women had lower self-assessment scores, especially in Community Mobility, Personal Care, and Participation in Society. However, the professionals only evaluated women lower in Community Mobility and men in Activities of Daily Living. Age was associated with a lower rating in personal care. Likewise, an increased number of admissions was related to a more negative evaluation in Understanding and Communicating. In contrast, those who had lower levels of education presented a lower Understanding and Communicating and were not capable of carrying out Activities of Daily Living. On the other hand, those who lived with their family had better ratings in Community Mobility, although only patients found this.

In short, SMD causes a significant disability ${ }^{(24)}$ in those who suffer from it. This disease is associated with functional problems, including the social and occupational functionings ${ }^{(25)}$. Therefore, adherence to a socio-occupational routine for people with SMD is complex, and a possible explanation is based on the functional impairment of such a diverse population ${ }^{(26)}$.

In addition to following the Model of Human Occupation ${ }^{(27)}$, this study considered the environment ${ }^{(28)}$ and cultural variables during activities since these factors could influence the performance of each activity.

\section{Conclusion}

In conclusion, intervention programs conducted by occupational therapy together with psychopharmacological treatment have assisted in improving performance and occupational interests in 
SMD. This improvement is perceived by patients and professionals alike after the treatment in the Medium Stay Unit.

\section{List Of Abbreviations}

ADLs; Activities of Daily Living

$\mathrm{CM}$; Community Mobility

IR; Interpersonal Relationships

IRP; Individual Recovery Plan

M; Mean

OT; occupational therapist

PC; Personal Care

PS; Participation in Society

SD; Standard Deviation

SMD; Severe mental disorder

UC; Understanding and Communicating

URME; Regional Unit for Medium Stay

WDA; Work and Daily Activities

WHODAS; World Health Organization Disability Assessment Schedule

\section{Declarations}

\section{Ethics approval and consent to participate}

The Bioethics Committees approved the study of the Virgen de la Arrixaca Hospital of the Region of Murcia and the Autonomous Community of Murcia (2016). Study participants signed the informed consent form.

\section{Consent for publication}

Not applicable.

\section{Availability of data and materials}


The data sets used and / or analyzed during the current study are available from the corresponding author upon reasonable request.

\section{Conflict of interests}

The authors declare not to have any interest conflicts.

\section{Funding}

This study has not received any type of funding.

\section{Authors' contributions}

All authors made significant contributions to the conception and design of the study. The authors critically reviewed the article and gave their final approval before submitting it.

\section{Acknowledgments}

The authors wish to thank all the participants who in one way or another have collaborated in this research.

\section{References}

${ }^{1}$ American Psychiatric Association. Diagnostic and statistical 234 manual of mental disorders. 4th ed. [tex. rev.]. Washington, DC: American Psychiatric Association; 2000.Available from: http://www.psychiatryonline.com/DSMPDF/dsm-iv.pdf

${ }^{2}$ ICD-10 International statistical classification of diseases and health-related problems. 10th ed. rev. Washington: World Health Organization; 2003.Available from: https://iris.paho.org/bitstream/handle/10665.2/6282/Volume1.pdf

${ }^{3}$ National Institute of Mental Health. Towards a model for a comprehensive community based mental health system. Washington DC: NIMH; 1987.Available from: https://www.imserso.es/InterPresent1/groups/imserso/documents/binario/atenenfermental.pdf

${ }^{4}$ D. Patiño, V. Zuleta, L. Londoño, L. Ramírez, E. Viveros. Family support during the treatment of patients with a diagnosis of mental illness. Rev Colomb Cienc Soc, 2012; 3: 243-258

Available from: https://dialnet.unirioja.es/servlet/articulo?codigo=5123797

${ }^{5}$ Kurzban S, Davis L, Brekke JS. Vocational, social, and cognitive rehabilitation for individuals diagnosed with schizophrenia: a review of recent research and trends. Curr Psychiatry Rep. 2010; 12: 345-55.Available from: https://doi.org/10.1007/s11920-010-0129-3

${ }^{6}$ Eberhard A, Torrico P. Short-stay Occupational Therapy in Mental Health in a primary care clinic. Occupational therapy in short term mental health care in a private clinic. RevChil Ter Ocup. 2013; 13: 45-55.Available from: https://pesquisa.bvsalud.org/portal/resource/pt/lil-768943 
${ }^{7}$ During P, Noya B. Occupational therapy in mental health principles and practice. Barcelona: Masson; 2002.

${ }^{8}$ Statement on occupational therapy. World Federation of Occupational Therapists; August 2011; 1. Available from: http://www.wfot.org/Portals/0/PDF/STATEMENT ON OCCUPATIONAL THERAPY 300811.pdf

${ }^{9}$ Kielhofner G. A model of human Occupation Theory and Application. 3rd ed. Baltimore: Lippincot, Williams and Wilkins; 2002.

${ }^{10}$ Browner WS, Black D, Newuman TB, Hulley SB. Estimation of sample size and power. In: Hulley SB, Cummings SR. Editors. Design of Clinical Research, an epidemiological approach. Spain: Harcourt Brace, 1997: 153-165.

${ }^{11}$ Daniel WW. Some important sampling distributions. In: Daniel WW Editor. Biostatistics. Basis for the analysis of health sciences. USA: Noriega 1994: 137-220.

${ }^{12}$ Siegel S. The level of significance and the size of the sample. In: Siegel S. Editor. Nonparametric statistics applied to the behavioral sciences. USA: Trillas 1994: 25-37.

${ }^{13}$ Chisolm, T. H, Abrms, H. B, McArdle, R., Wilson, R. H \& Doyle, PJ The WHO-DAS II: psychometric properties in the measurement of functional health status in adults with acquired hearing loss. Trends in Amplification. 2005; 9 (3), 111-126.Available from:

https://www.ncbi.nlm.nih.gov/pmc/articles/PMC4111522/

${ }^{14}$ Üstün, TB, Chatterji, S., Kostanjsek, N., Rehm, J. Measuring Health and Disability: WHO Disability Assessment Schedule (WHODAS 2.0). Genova, Switzerland: Author; 2010.

Available from: https://apps.who.int/iris/handle/10665/43974

${ }^{15}$ Paniagua G. Validation of the World Health Organization questionnaire for the evaluation of disability in the clinical population of the metropolitan area of San Salvador and Santa Ana. CREACIENCIA [Internet]. Dec 27, 2017 [cited March 4, 2021]; 11 (1-2): 53-9.Available from:

https://www.camjol.info/index.php/CREACIENCIA/article/view/6040

${ }^{16}$ Ruiz-Ruiz JC, García-Ferrer S, Fuentes-Durá I. The social relevance of social cognition in schizophrenia. Notes of Psychology. 2006; 24: 137-55. Available from:

http://www.apuntesdepsicologia.es/index.php/revista/article/view/74/76

${ }^{17}$ Berrueta LM, Bellido Mainar JR. Social factors that influence mental health. In: Sánchez Rodríguez, Oscar, Polonio López, Begoña and Pellegrini Spangenberg, Mariel. Occupational therapy in mental health theory and techniques for personal autonomy. Madrid: Pan-American, 2013. p 33-44.

${ }^{18}$ Boden, R. Sundström, J. Lindström, E. Lindström, L. Association between symptomatic remission and functional outcome in fist-episode schizophrenia. Schizophr Res 2009; 107: 232-237.DOI: 
https://doi.org/10.1016/j.schres.2008.10.004

${ }^{19}$ Valencia CM. Psychosocial intervention program for chronic schizophrenic patients. In Mental Health Vol (22), pp128-37.1999Available from:

http://www.revistasaludmental.mx/index.php/salud_mental/article/view/794/793

${ }^{20}$ Rossell SL, Coakes J, Shapleske J, Woodruff PWR, David AS. Insight: Its relationship with cognitive function, brain volume and symptoms in schizophrenia. Psychol Med. 2003; 33: 111-9.DOI:

https://doi.org/10.1017/S0033291702006803

${ }^{21}$ Wilder-Willis KE, Shear PK, Steffen JJ, Borkin J. The relationship between cognitive dysfunction and coping abilities in schizophrenia. Schizophr Res. 2002; 55: 259-67.DOI: https://doi.org/10.1016/S09209964(01)00211-0

${ }^{22}$ Nuechterlein KH, Barch DM, Gold JM, Goldberg TE, Green MF, Heaton RK. Identification of separable cognitive factors in schizophrenia. Schizophr Res. 2004; 72: 29-39.DOI:

https://doi.org/10.1016/j.schres.2004.09.007

${ }^{23}$ Green MF. What are the functional consequences of neurocognitive deficits in schizophrenia? Am J Psychiatry 1996; 153: 321-30.DOI: https://doi.org/10.1176/ajp.153.3.321

${ }^{24}$ AEN working group (GTR-AEN). Psychosocial rehabilitation of severe mental disorder. Situation and recommendations. Technical notebook, 6. Madrid: Spanish Association of Neuropsychiatry; 2002.Available at: http://www.ome-aen.org/groups/CuadernoTecnico6Rehabi.pdf

${ }^{25}$ Kleinman, L. Lieberman, J. Dube, S. Mohs, R. Zhao, Y. Kinon, B. et al. Development and psychometric performance of the schizophrenia objective functioning instrument: An interviewer administered measure of function. Schizophr Res 2009; 107: 275-285.DOI: https://doi.org/10.1016/j.schres.2008.10.002

${ }^{26}$ Aubin, G. Stip, E. Gélinas, I. Rainville, C. Chapparo, Ch. Daily functioning and information-processing skills among persons with schizophrenia. Psychiatric Services 2009; 60 (6): 817-822.DOI: https://doi.org/10.1176/ps.2009.60.6.817

${ }^{27}$ Kielhofner G. Conceptual foundations of occupational therapy practice. Cuarta edición. Philadelphia, PA: F.A. Davis Company; 2009.

${ }^{28}$ Maciver D, Morley M, Forsyth K, Bertram N, Edwards T, Heasmane D, et al. Innovating with the Model of Human Occupation in Mental Health. Occup Ther Ment Heal. 2015; 31(2):144-54. DOI:

https://doi.org/10.1080/0164212X.2015.1029603 